\title{
Course of scar quality of donor sites following split skin graft harvesting: Comparison between patients and observers
}

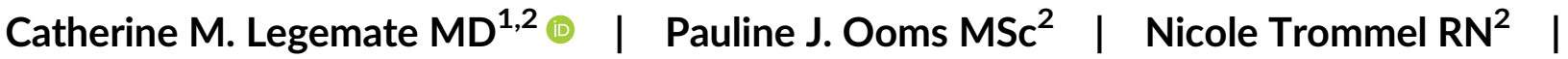 \\ Harold Goei MD, PhD ${ }^{3}$ | Ymke Lucas MD $^{2}$ | Esther Middelkoop PhD ${ }^{1,4}$ | \\ Margriet E. van Baar PhD ${ }^{2,5}$ ～Cornelis $\mathrm{H}$. van der Vlies MD, PhD ${ }^{2,5,6}$
}

\author{
${ }^{1}$ Department of Plastic, Reconstructive and \\ Hand Surgery, Amsterdam Movement \\ Sciences, Amsterdam UMC, Vrije Univeristeit \\ Amsterdam, Amsterdam, the Netherlands \\ ${ }^{2}$ Maasstad Hospital, Burn Center, Rotterdam, \\ the Netherlands \\ ${ }^{3}$ Department of Surgery, Amsterdam \\ Movement Sciences, Amsterdam UMC, Vrije \\ Univeristeit Amsterdam, Amsterdam, the \\ Netherlands \\ ${ }^{4}$ Association of Dutch Burn Centres, Red \\ Cross Hospital, Beverwijk, the Netherlands \\ ${ }^{5}$ Department of Public Health, Erasmus MC, \\ University Medical Center Rotterdam, \\ Rotterdam, the Netherlands \\ ${ }^{6}$ Trauma Research Unit, Department of \\ Surgery, Erasmus MC, University Medical \\ Center Rotterdam, Rotterdam, the \\ Netherlands

\section{Correspondence} \\ Cornelis H. van der Vlies, Maasstad Hospital, \\ Burn Center, Maasstadweg 21, 2079DZ \\ Rotterdam, the Netherlands. \\ Email: vliesc@maasstadziekenhuis.nl \\ Funding information \\ The Dutch Burns Foundation, Grant/Award \\ Number: 15.101
}

\begin{abstract}
There exists little to no data on the development of donor-site scars that remain after split skin graft harvesting. The objectives of this study were to (a) examine changes in characteristics of donor-site scar quality over time and (b) assess the agreement between patient-reported and observer-reported donor-site scar quality in a burn population. A prospective cohort study was conducted including patients who underwent split skin grafting for their burn injury. Patients and observers completed the Patient and Observer Scar Assessment Scale (POSAS) for the first harvested donor site at 3 and 12 months post-surgery. This study included 80 patients with a median age of 34 years. At 3 months post-surgery, the patients scored the POSAS items itch and color as most deviant from normal skin, both improved between 3 and 12 months ( 3.1 vs 1.5 and 5.0 vs 3.5 , respectively $[P<.001]$ ). Other scar characteristics did not show significant change over time. The patients' overall opinion score improved from 3.9 to $3.2(P<.001)$. Observers rated the items vascularization and pigmentation most severe, only vascularization improved significantly between both time points. Their overall opinion score decreased from 2.7 to $2.3(P<.001)$. The inter-observer agreement between patients and observers was considered poor $($ ICC $<0.4)$ at both time points. Results of current study indicate that observers underestimate the impact of donor-site scars. This has to be kept in mind while guiding therapy and expectations.

LEVEL OF EVIDENCE: II, prospective cohort study.
\end{abstract}

\section{1 | BACKGROUND}

Split skin grafting remains a widely used reconstructive technique for chronic wounds, burns, and other traumatic wounds. The procedure involves harvesting of the full epidermis and part of the dermis, creating a secondary wound at the donor site. Because skin grafting is necessary to cover the wound, scars of these donor sites might be considered as subservient. Unlike for other wounds, there is little to

Abbreviations: POSAS, Patient and Observer Scar Assessment Scale; TBSA, total body surface area. no data on the development of donor-site wounds and their final appearance, even though the donor site can be a considerable burden to patients during and after the healing process. ${ }^{1,2}$

Integrating scar evaluations of patients in clinical assessments is promoted based on findings that patient-rated scar severity is directly related to psychological distress, whereas observer-rated scar severity is unrelated to psychological distress. ${ }^{3}$ Assessment of scars by both patients' and professionals' provides more useful information regarding the patients' wellbeing compared to focusing on the separate assessments only. ${ }^{4}$

Eskes et al investigated patients' and observers' judgments and satisfaction with respect to donor-site scars at 3 months after wound 
healing. ${ }^{5}$ They found discrepancies between patients' and observers' opinions on different characteristics of donor-site scars. ${ }^{5}$ However, they included mainly male patients who underwent surgery in a nonacute setting and only included adults with a mean age of 59.6 years. $^{6}$ Furthermore, scars were assessed at 12 weeks post-surgery, which limits the insight into the final situation of the scar as the active transformation processes and maturation of scars takes at least 1 year. $^{7-9}$

The objectives of this study were to (a) examine changes in characteristics of donor-site scar quality over time and get insight into final scar appearance at 12 months post-surgery and (b) to assess the extent of agreement between patients' ratings and observers' rating of donor-site scar characteristics in a burn population. The ultimate aim of the current study was to improve information given to patients and eventually ensure high-quality patient-centered care.

\section{PATIENTS AND METHODS}

\subsection{Study design and patients}

An observational prospective cohort study was performed. From February 2016 to February 2017, patients were included in the burn center of the Maasstad Hospital in Rotterdam, the Netherlands. Patients of all ages who underwent split skin grafting for an acute burn were eligible to participate. Patients were excluded if they had cognitive impairments or were unable to understand or answer questionnaires in Dutch or English. Written informed consent was obtained from each patient and patients received standard treatment. Strengthening the Reporting of Observational Studies in Epidemiology (STROBE) guidelines were adhered to in this study and manuscript. The study was approved by the regional Medical Ethics Committee (reference number L2016119) and conducted according to the principles of the Declaration of Helsinki. Scar quality of the first harvested donor site was evaluated at 3 and 12 months post-surgery during routine outpatient visits. Other study parameters were documented during admission, surgery, and outpatient visits. These were patient characteristics: age at surgery, gender, and skin type. Registered clinical characteristics were burn-related: \% total burned body surface area (TBSA), \% TBSA excised, length of stay, and donor site-related: location on the body, >2 weeks to re-epithelization, and wound infection.

\section{2 | Treatment}

Patients received standard treatment peri-operatively. Split-thickness skin grafts were harvested at a depth of $0.2 \mathrm{~mm}$ (0.007 in.) with an electric dermatome. Adrenaline soaked alginate dressings were place on the wounds immediately after grafting to reduce blood loss. Afterward, donor-site wounds were covered with an alginate dressing, cotton wool and elastic bandages, which were removed 2 weeks postsurgery.

\subsection{Scar outcome}

The Patient and Observer Scar Assessment Scale (POSAS) version 2.0 was used to assess scar quality. ${ }^{10}$ The POSAS is a validated measurement scale for scar quality of burn and linear scars and therefore seemed most suitable to assess scar quality of donor sites. ${ }^{10-13}$ The POSAS consists of a patient and observer (ie, caregiver) part. Both patient and observers rated the same scar on six different scar characteristics, with roughly an overlap of four characteristics (Table 2). This enabled the identification of differences between patients and observers and specific scar characteristics that may be more troublesome than others from the patients' point of view.

The patient part involves the scar characteristics pain, itch, color (a combination of vascularization and pigmentation), thickness, relief (surface roughness), and pliability (stiffness). The parameters pain and itch measure the extent to which the donor-site scars have been painful or itching over the past few weeks. The parameters color, thickness, and pliability describe the patients' judgment of whether the color, thickness, and stiffness of the donor-site scar differed from the normal skin. The parameter relief, which includes the surface roughness of the donor-site scar area, described the presence of surface irregularities. The observer scale includes vascularization, pigmentation, thickness, surface, relief, and pliability. Each of the six scar characteristics was rated on a 10-point scale, which ranges from 1 (comparable to normal skin) to 10 (very different from normal skin).

In addition, patients and observers complete 1 item to measure their overall opinion on the donor-site scar, ranging from 1 (best scar imaginable) to 10 (worst scar imaginable).

\subsection{Statistical analysis}

\subsection{1 | Characteristics}

Descriptive statistics were used to present data on patient characteristics (age, sex, and Fitzpatrick skin type), clinical characteristics (cause of the burn, percentage total body surface area [TBSA] burned, percentage TBSA excised, and length of stay), and donor-site characteristics (anatomical location of the donor site, $>2$ weeks to re-epithelization, infection).

\subsection{2 | Changes of scar quality over time}

The Wilcoxon signed-rank test was used to analyze differences per POSAS item between 3 and 12 months. A P-value <.05 was considered significant. Additionally, the effect size was calculated by dividing the Z-value by the square root of number of cases. An effect size above 0.5 was considered as a "large effect," between 0.3 and 0.5 as a "moderate effect" and between 0.1 and 0.3 as a "small effect" and beneath 0.1 "trivial." In other words, the larger the effect size, the greater the change in scar quality. ${ }^{14}$ 


\subsection{3 | Agreement between patients and observers}

The agreement between patients and observers on the POSAS items was assessed in three ways. First, the inter-observer reliability (IOR) was used to determine the agreement between the patient-ratings and observer-ratings regarding the different items on quality of the donor-site scars. The IOR was expressed as intra-class correlation coefficient (ICC) for the POSAS items, including their 95\% confidence intervals $(\mathrm{Cl})$, and calculated using a two-way mixed random effect model for single measures consistency. ${ }^{15,16}$ The ICC was calculated for the corresponding items (color, vascularity, pigmentation, relief, and thickness) and overall opinion item. To be able to compare the color assessments of the patients with the color assessments of the professionals, an average score for the items vascularity and pigmentation was calculated. ICC values range from no agreement (0) to perfect agreement (1). ${ }^{17,18}$ ICC values beneath 0.4 are considered as "poor agreement," between 0.4 and 0.6 as "moderate agreement," between 0.6 and 0.8 as "good agreement" and above 0.8 as "very good agreement". ${ }^{17,18}$ Second, the $95 \%$ limits of agreement approach (Bland and Altman plots) were used to assess the score agreement between the patients' and observers' judgment of the overall opinion. ${ }^{19,20}$ Third, a sub analysis on the corresponding POSAS items was performed to analyze whether the patients judged their scars more severe, identical or less severe compared to the observers. All data analyses were performed using statistical software (IBM, SPSS, V.24.0).

\section{3 | RESULTS}

Out of 113 eligible patients, 80 patients were included in the study. Participants had a median age of 34 (range 0-84) and most were male (65.0\%). Median percentage TBSA burned was 6.0 (range 0.5-55) and most donor sites were placed on the thigh (73.8\%) (Table 1). During 3-month follow-up, 73 patients (91\%) completed the POSAS. During 12-month follow-up, 72 patients (90\%) completed the POSAS (Figure 1). A nonresponse analysis showed no differences in age, gender, and \%TBSA burned.

\subsection{1. | Scar quality and changes over time}

At 3 months post-surgery, the patients rated the scar characteristics color and itch most severe (Figure 2). The mean scores for color and itch significantly decreased (eg, improved) between 3 and 12 months (3.1 vs 1.5 and 5.0 vs 3.5 , respectively, both $P<.001$ ) with an effect size of 0.53 and 0.48 , indicating a moderate effect. No significant change was seen for the other items (Figure 2, Supplementary Digital Content S1), but the mean overall opinion of the patients significantly decreased from 3.9 to 3.2 (effect size $0.49, P<.001$ ).

The observers rated the characteristics vascularization and pigmentation most severe at 3 months post-surgery (3.3 and 2.5, respectively) (Figure 2, Supplementary Digital Content S1). The mean item scores of vascularization and pliability decreased significantly with an
TABLE 1 Baseline characteristics

\begin{tabular}{|c|c|}
\hline Demographics & Total population $(n=80)$ \\
\hline Age, median (range) & $34(0-84)$ \\
\hline Male, $\mathrm{n}(\%)$ & $52(65.0)$ \\
\hline Skin type [FP >3], n (\%) & $21(26.4)$ \\
\hline \multicolumn{2}{|l|}{ Clinical characteristics } \\
\hline \multicolumn{2}{|l|}{ Cause of the burn } \\
\hline Scald (\%) & $19(23.8)$ \\
\hline Flame/fire (\%) & $39(48.8)$ \\
\hline Hot fat (\%) & $4(5.0)$ \\
\hline Other (\%) & $18(22.5)$ \\
\hline \%TBSA burned, median (range) & $6(0.5-55)$ \\
\hline \%TBSA excised, median (range) & $2(0.5-50)$ \\
\hline LOS in days, median (range) & $16(0-94)$ \\
\hline \multicolumn{2}{|l|}{ Donor-site characteristics } \\
\hline \multicolumn{2}{|l|}{ Location of the donor-site } \\
\hline Thigh (\%) & $59(73.8)$ \\
\hline Other (\%) & $21(26.4)$ \\
\hline Time to re-epithelization (>2 weeks), n(\%) & $58(74.4)$ \\
\hline Wound infection, $\mathrm{n}(\%)$ & $7(8.8)$ \\
\hline
\end{tabular}

Abbreviation: TBSA, total burned body surface area.

effect-size of 0.84 (large effect, $P<.001$ ) and 0.2 (small effect, $P<.05)$, respectively. The mean overall opinion of the observers significantly decreased from 2.7 to 2.3 (effect size $0.46, P<.001$ ).

\subsection{2. | Agreement between patients and observers}

Table 2 shows the agreement in terms of inter-observer agreement between patients and observers on the corresponding POSAS items. The agreement on the items pliability, thickness, and relief increased between 3 and 12 months. Agreement on POSAS items was all poor; however, at 12 months, at best for the item color/pigmentation (0.38, 95\% Cl: 0.16-0.56).

The limits of agreement approach showed that $95 \%$ of the patient overall opinion item differed up to 4.74 points from the observers with a systematic difference of 1.05 at 3 months and 0.89 at 12 months, indicating a slightly better agreement between the assessors at 12 months. Both plots visualize that the difference between the patients and observers tends to get larger as the average overall opinion score increases (ie, if the overall opinion gets worse) (Figure 3).

Figure 4 presents the agreement in terms of the proportion of patients that score their scar more severe, identical or less severe compared to the observer. Patient and observer scar assessment scores of the items relief and pliability were identical in more than $50 \%$ of the cases, whereas the agreement on color (vascularity and pigmentation) was below $20 \%$ at both time points. Overall, patients rated the scar characteristic color (pigmentation and vascularization) 


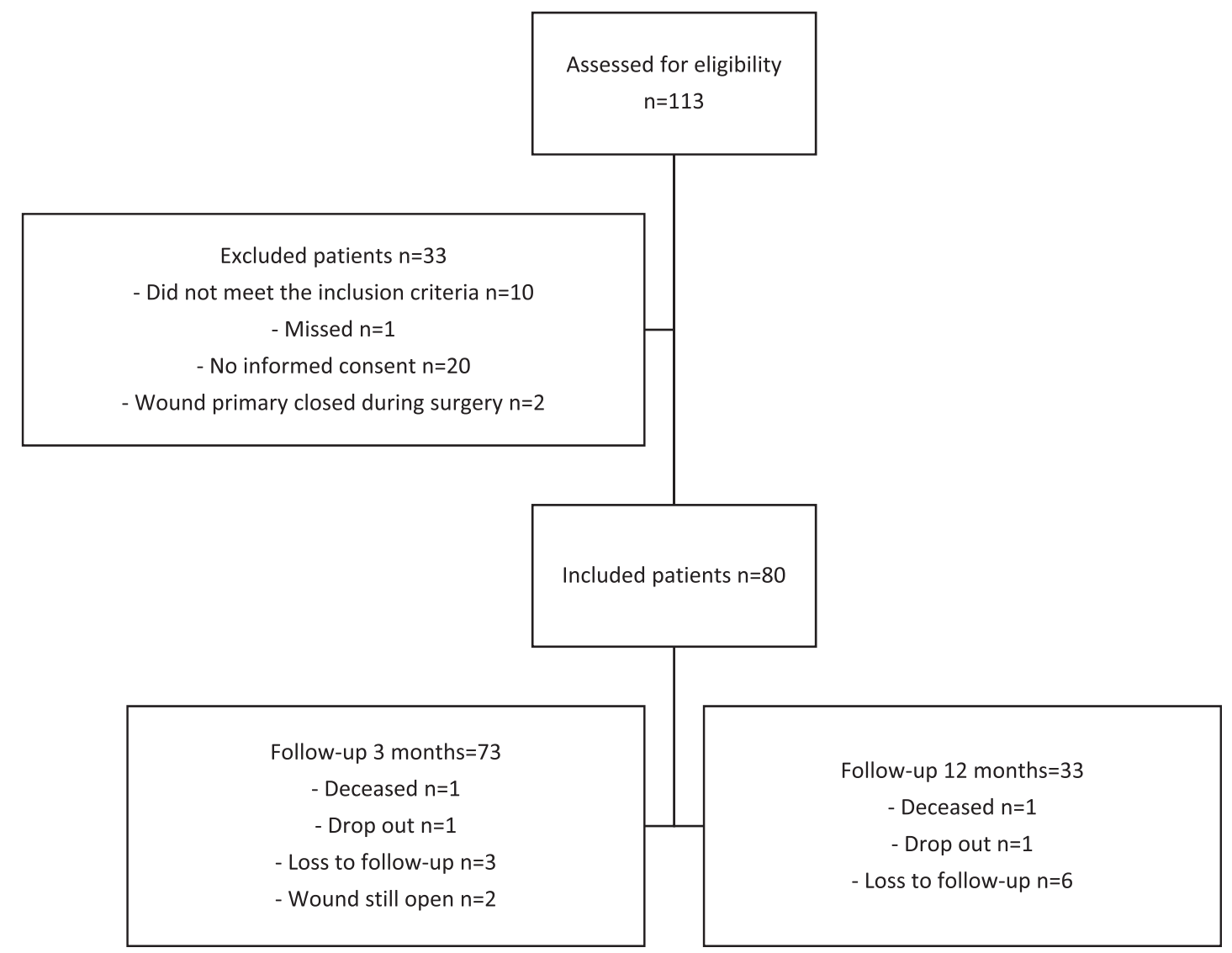

FIGURE 1 Inclusion flowchart

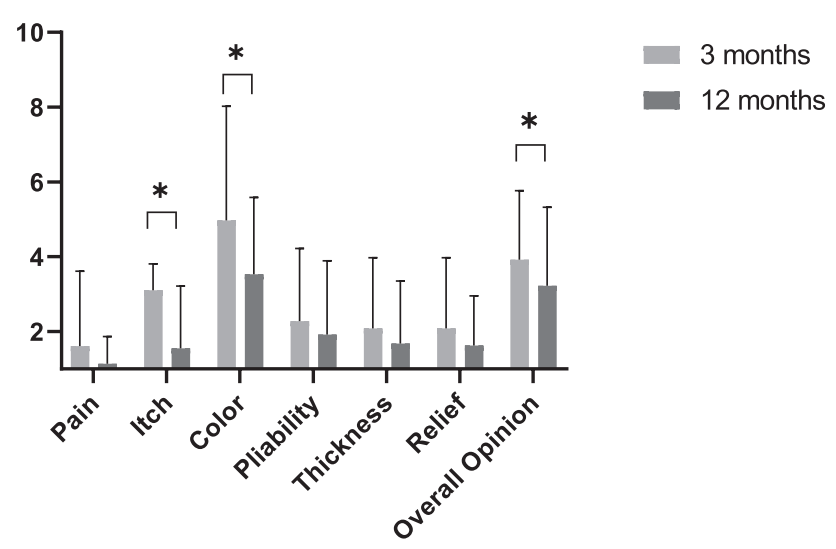

Patient part of the POSAS

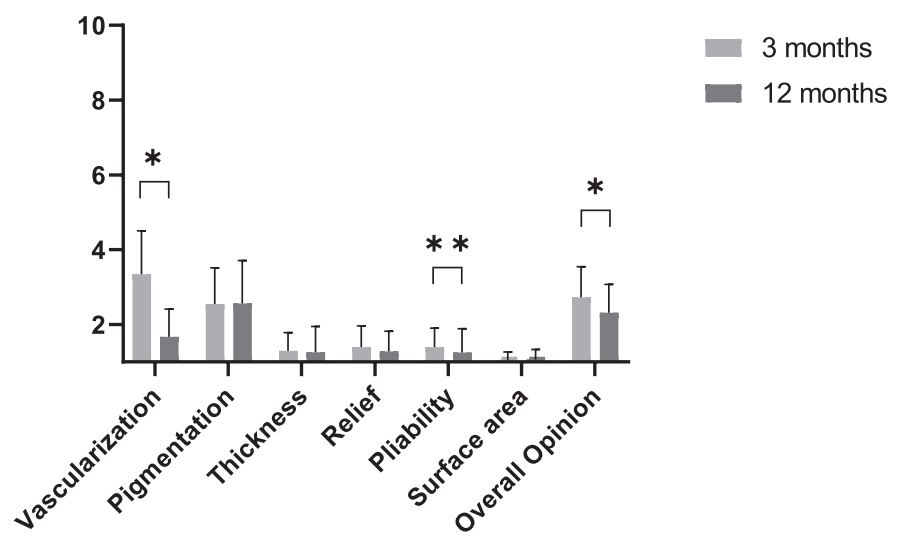

Observer part of the POSAS

FIGURE 2 Patients and Observers (ie, caregivers) Scar Quality scores at 3 and 12 months post-surgery. Bars represent the mean item score and SD. A lower Patient and Observer Scar Assessment Scale (POSAS) score correlates with a better scar; a score of 10 reflects the worst imaginable scar. A score of 1 means no difference from normal skin. ${ }^{*} P<.001,{ }^{* *} P<.05$ (Wilcoxon signed-rank test)

and their overall opinion on the scar more severe than observers. If patients rated their scar less severe than observers, the mean difference was less than one point for all items (Supplementary Digital Content S2). If patients rated the scar more severe than observers, the mean difference was more than two points for all items (Supplementary Digital Content S2).

\section{4 | DISCUSSION}

To our knowledge, this is the first study that investigated patient- and observer-reported scar quality of donor sites up to 1 year post-surgery. Patients' and observers' perceptions of scar quality only slightly improved during scar maturation. The agreement between patients 
and observers generally increased between 3 and 12 months but remained "poor" for all items of the POSAS. Results of this study indicate that caregivers seem to underestimate the impact of scars on patients. Especially the items on color were rated more severe by patients.

The magnitude of the observed improvement in scar quality over time was limited in our study population. Patient satisfaction regarding donor sites may improve over time as a result of scar maturation but may on the other hand deteriorate as a result of psychological sequelae, especially when the recipient site is completely healed and the patient might have expected that the donor-site scar would fade. The small changes over time that we observed in the perception of scar quality and satisfaction are consistent with previous studies on other scar types. ${ }^{7,9}$ Our results show that items on color (color on the patients scale, vascularization, and pigmentation on the observer scale) are rated

TA B LE 2 Inter-observer reliability between patients and caregivers

\begin{tabular}{|c|c|c|}
\hline POSAS items & 3 months ICC $(95 \% \mathrm{CI})$ & 12 months ICC (95\% Cl) \\
\hline Color/vascularity & 0.29 (0.07 to 0.49) & $0.14(-0.09$ to0.36) \\
\hline Color/pigmentation & 0.05 (0.28 to 1.11$)$ & 0.38 (0.16 to 0.56$)$ \\
\hline Color/combination ${ }^{a}$ & 0.08 (0.30 to 1.17$)$ & $0.20(-0.03$ to 0.41$)$ \\
\hline Pliability & 0.30 (0.08 to 0.50$)$ & 0.31 (0.09 to 0.54$)$ \\
\hline Thickness & $0.19(-0.05$ to 0.40$)$ & $0.36(0.15$ to 0.55$)$ \\
\hline Relief & $0.23(-0.01$ to 0.44$)$ & $0.36(0.14$ to 0.54$)$ \\
\hline Overall opinion & $0.20(-0.02$ to 0.41$)$ & 0.24 (0.02 to 0.45$)$ \\
\hline
\end{tabular}

Note: ICC values range from no agreement $(0)$ to perfect agreement (1). ${ }^{17,18}$ ICC values beneath 0.4 are considered as "poor agreement," between 0.4 and 0.6 as "moderate agreement," between 0.6 and 0.8 as "good agreement" and above 0.8 as "very good agreement."17,18

Abbreviation: ICC, intra-class correlation coefficient; POSAS: Patient and Observer Scar Assessment Scale.

${ }^{a}$ Combination: Average score of vascularity and pigmentation. the worst out of all items by both patients and observers at both time-points. Patients rated color less severe at 12 months postsurgery while observers only rated the item vascularization less severe at 12 months post-surgery. This might indicate that the appreciation of the item "color" grows as a result of the reduction of erythema and that pigment changes contribute less to the improvement. This is in line with one study that measured erythema and melanin indexes of donor site scars with an objective measurement instrument in patients with chronic leg ulcers. ${ }^{2}$ That study found that the erythema index decreased $109 \%$ from 3 to 12 months post-surgery, while pigmentation only decreased $24 \%$ compared to normal skin. Studies that investigated patient- and observer-reported scar quality of burn wounds also found that items on color were rated worse than other items. ${ }^{7,21}$ The severe scores and reduction over time that we found for patientreported itching are also in accordance with previous studies regarding burn and linear scars. ${ }^{7,12,13}$

The items pliability, thickness, and relief seem of less importance in our study population than to populations with burn scars or linear scars. ${ }^{7,12,13}$ Nevertheless, it is of note that none of the POSAS items had a mean score of 1 (ie, the same as normal skin) at 12 months post-surgery.

Patients and observers showed only poor-to-moderate agreement on scar quality at both time points. For the overall opinion on the scar, agreement was poor as well. Patients especially scored color worse than observers, while observers seemed to underline the importance of thickness. This might be due to the fact that hypertrophy of donor-site scars is not expected by the observers and may be seen as pathological scarring, while patients might compare the donor-site scar to their burn scar and consequently downgrade hypertrophy. The limited agreement on specific items that we found between patients and observers is consistent with studies that reported differences in scar appreciation between patients and observers on linear scars. ${ }^{5,22-24}$ Eskes et al only found a "moderate" agreement on the overall opinion item of the POSAS on donor-site scars in a general trauma population and also a
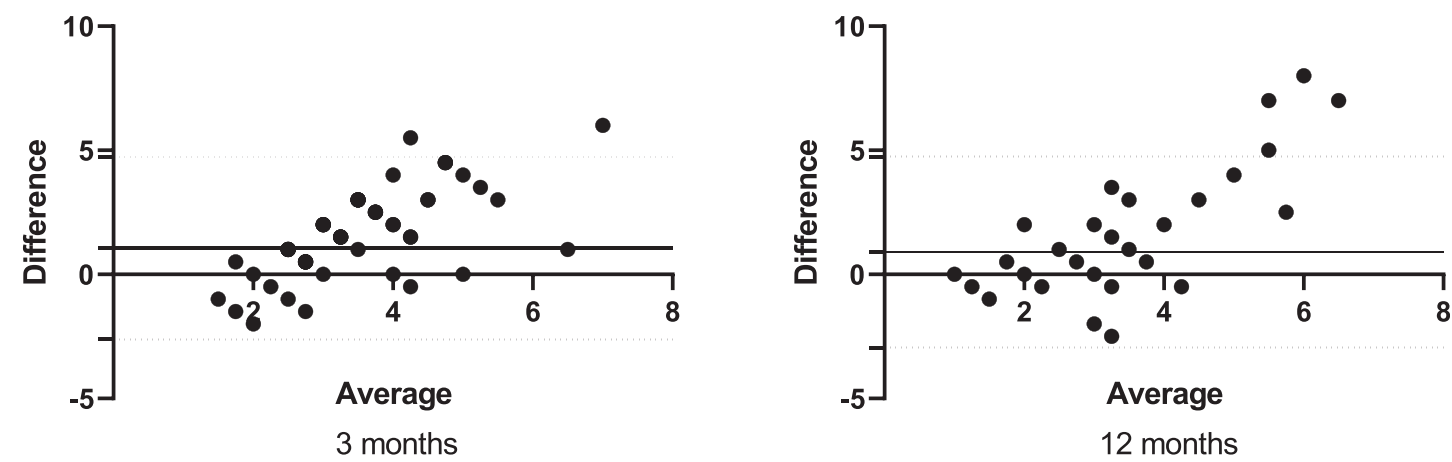

FIGURE 3 Bland and Altman plots demonstrating the agreement of Patient and Observer Scar Assessment Scale (POSAS) overall opinion scores between patients and caregivers at 3 (left) and 12 (right) months post-surgery. Each dot in the figure represents a donor-site scar judged by the patient and observers. The difference between the two ratings is on the $\mathrm{Y}$-axis and the average of both ratings on the $\mathrm{X}$-axis. The dotted lines represent the $95 \%$ confidence intervals (limits of agreement -2.63 to 4.74 and -2.95 to 4.74 ) and the black line the mean difference between the raters (mean difference 1.055 and 0.892) 


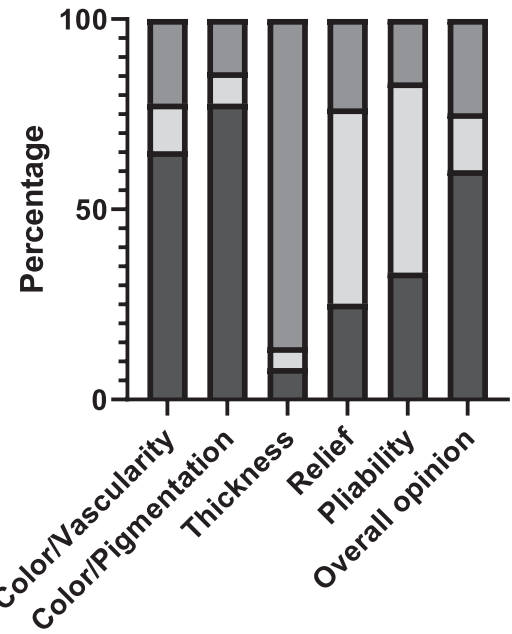

3 months

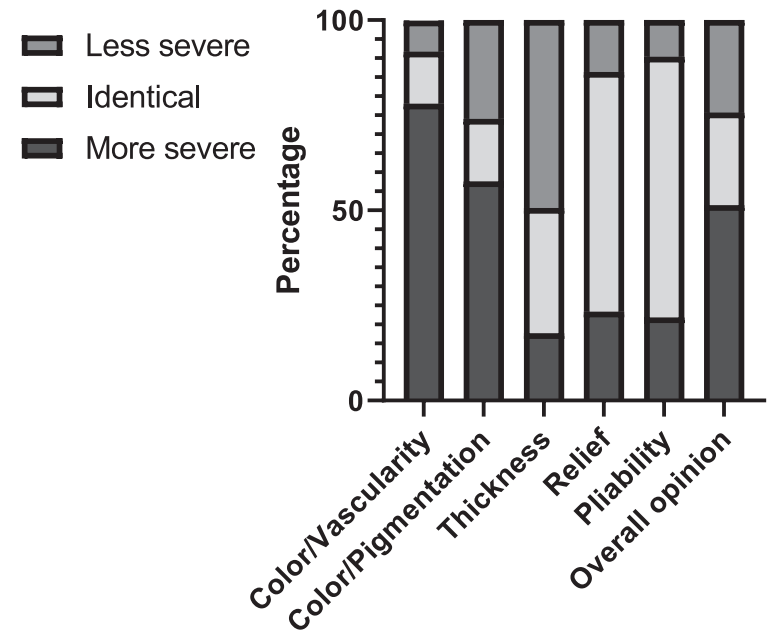

12 months

FIGURE 4 The agreement in terms of the proportion of patients that score their scar quality more severe, identical or less severe compared to the observer

"poor" agreement for all other items. However, they did not study the magnitude or direction of the differences between patients' and observers'. ${ }^{5}$ Hoogewerf et al studied the magnitude and direction of differences in assessment of facial burn scars for patients and observers in a Dutch burn population. ${ }^{4}$ They found that $53 \%$ of the patients' and observers' assessments were identical. In our study population, this was only $24 \%$ and $37 \%$, at, respectively, 3 and 12 months. In other words, there seems to be a worse agreement in the judgment of donor-site scars compared to the recipient site.

Surgeons should be aware of the fact that patients might have different views on scar outcomes after split skin grafting. Patients are often well informed on the (development of) scars at the recipient site, but just have to deal with the emergence of a donor-site scar. Our results can be used to manage patients expectations regarding donor-site scar quality after split skin grafting. Effective communication can improve patient satisfaction and outcome. However, it is difficult to predict psychological distress based on the severity of disfigurement. Therefore, future studies should investigate the relationship between donor-site scar quality and psychological distress or quality of life. ${ }^{25}$ Results of our study can also be used as a starting point for scar quality improvement. Concerns about donor-site scarring may be more significant than surgeons might expect; the mean overall opinion of the patient on the donor-site scar was still 3.2 after 1 year (in comparison: two large cohort studies found that patients scored the overall opinion on their burn scar 4.1 , at $1-\geq 5$ years post burn ${ }^{7,21}$ ). Many studies have been performed on donor-site management ranging from different types of wound dressings to more innovative (surgical) techniques, including harvesting of the skin from a different location (ie, buttock or skull) or the use of other harvesting methods, like dermal grafting. ${ }^{26-29}$ Caregivers should be aware of these options, which may increase scar quality.
However, most studies on the outcomes of these treatment options focus on early and rapid re-epithelialization but lack data on patient reported (long term) scar appearance. ${ }^{26}$ Further research is, therefore, necessary to investigate which patients benefit from these techniques.

This study has limitations that should be noted. The POSAS was used to assess scar quality. Although this is the only scar assessment scale that takes the opinion of the patient into account and has been validated for judgment of burn and linear scars, there has never been a reference or golden standard with regard to the quality of scars. In our study, this is of less importance because the patients' perception is the ultimate outcome to come to the best patient-centered care. Nevertheless, a minimal important change analysis is never done for the POSAS and it is therefore unknown if patients or observers judged the observed changes between 3 and 12 months important or meaningful. Another limitation is that this study is part of an explorative cohort study wherefore it was decided a priori to include patients over a 1-year period. The accuracy of the agreement might be limited as illustrated by the wide confidence intervals and might be due to an insufficient sample size. However, the agreement between items was "poor" at best. So even if the number of included patients would decrease confidence limits, this will probably not lead to a "good" agreement.

\section{5 | CONCLUSION}

The agreement on donor-site scar quality between patients and observers is limited. Surgeons should be aware that patients might have a different view on donor-site scars. This realization is important to manage patient expectations regarding scar quality after split skin grafting and pre-surgical counseling of patients with regard to 
anticipated anxiety about scar appearance and quality improvement. Effective communication may improve patient satisfaction.

\section{ACKNOWLEDGMENTS}

C. M. Legemate received a grant from The Dutch Burns Foundation to support this study (grant number: 15.101). The funder had no role in study design, data collection and analysis, decision to publish, or preparation of the manuscript.

\section{CONFLICT OF INTEREST}

The authors declare no potential conflict of interest.

\section{ORCID}

Catherine M. Legemate (D) https://orcid.org/0000-0001-7943-7747

\section{AUTHOR CONTRIBUTIONS}

Catherine Legemate conceptualized and designed the study, collected data, analyzed and interpreted data, drafted the initial manuscript, and reviewed and revised the manuscript. Pauline Ooms collected data, analyzed and interpreted data, and reviewed and revised the manuscript. Nicole Trommel conceptualized the study, collected data, interpreted data, and reviewed and revised the manuscript. Harold Goei conceptualized the study, interpreted data, and reviewed and revised the manuscript. Ymke Lucas collected data, interpreted data, and reviewed and revised the manuscript. Esther Middelkoop conceptualized and designed the study, interpreted data, and reviewed and revised the manuscript. Margriet van Baar conceptualized and designed the study, collected data, interpreted data, and reviewed and revised the manuscript. Cornelis van der Vlies conceptualized and designed the study, interpreted data, and reviewed and revised the manuscript. All authors approved the final manuscript as submitted and agree to be accountable for all aspects of the work.

\section{ORCID}

Catherine M. Legemate (D) https://orcid.org/0000-0001-7943-7747

\section{REFERENCES}

1. Garcia E, Stone E, Chan LS, Van Vliet M, Garner WL. Donor-site preferences in women during autologous skin grafting. Plast Reconstr Surg. 2014;133(3):378e-382e.

2. Danielsen PL, Jorgensen LN, Jorgensen B, Karlsmark T, Agren MS. Erythema persists longer than one year in split-thickness skin graft donor sites. Acta Derm Venereol. 2013;93(3):281-285.

3. Brown BC, Moss TP, McGrouther DA, Bayat A. Skin scar preconceptions must be challenged: importance of self-perception in skin scarring. J Plast Reconstr Aesthet Surg. 2010;63(6):1022-1029.

4. Hoogewerf CJ, van Baar ME, Middelkoop E, van Loey NE. Patient reported facial scar assessment: directions for the professional. Burns. 2014; 40(2):347-353.

5. Eskes AM, Brolmann FE, van de Kar AL, et al. Values of patients and caregivers for donor site scars: an inter-observer analysis between patients and caregivers and prediction of cosmetic satisfaction. Burns. 2012;38(6):796-801.

6. Dokter J, Vloemans AF, Beerthuizen $\mathrm{Gl}$, et al. Epidemiology and trends in severe burns in The Netherlands. Burns. 2014;40(7):14061414.
7. van der Wal MB, Vloemans JF, Tuinebreijer WE, et al. Outcome after burns: an observational study on burn scar maturation and predictors for severe scarring. Wound Repair Regen. 2012;20(5):676-687.

8. Bond JS, Duncan JA, Mason T, et al. Scar redness in humans: how long does it persist after incisional and excisional wounding? Plast Reconstr Surg. 2008;121(2):487-496.

9. Bond JS, Duncan JA, Sattar A, et al. Maturation of the human scar: an observational study. Plast Reconstr Surg. 2008;121(5):1650-1658.

10. Draaijers $L$, Tempelman FRH, Botman YAM, et al. The patient and observer scar assessment scale: a reliable and feasible tool for scar evaluation. Plast Reconstr Surg. 2004;113(7):1960-1965.

11. Tyack Z, Simons M, Spinks A, Wasiak J. A systematic review of the quality of burn scar rating scales for clinical and research use. Burns. 2012;38(1):6-18.

12. van de Kar AL, Corion LU, Smeulders MJ, Draaijers LJ, van der Horst CM, van Zuijlen PP. Reliable and feasible evaluation of linear scars by the Patient and Observer Scar Assessment Scale. Plast Reconstr Surg. 2005;116(2):514-522.

13. Truong PT, Lee JC, Soer B, Gaul CA, Olivotto IA. Reliability and validity testing of the Patient and Observer Scar Assessment Scale in evaluating linear scars after breast cancer surgery. Plast Reconstr Surg. 2007;119(2):487-494.

14. Cohen J. Statistical Power Analysis for the Behavioral Science. New York University, New York: Elsevier; 1988.

15. Shrout PE, Fleiss JL. Intraclass correlations: uses in assessing rater reliability. Psychol Bull. 1979;86(2):420-428.

16. McGraw KO, Wong SP. Forming inferences about some intraclass correlation coefficients. Psychol Methods. 1996;1(1):30-46.

17. Durani P, McGrouther DA, Ferguson MW. Current scales for assessing human scarring: a review. J Plast Reconstr Aesthet Surg. 2009;62(6):713-720.

18. Muller R, Buttner P. A critical discussion of intraclass correlation coefficients. Stat Med. 1994;13(23-24):2465-2476.

19. Bland JM, Altman DG. Statistical methods for assessing agreement between two methods of clinical measurement. Lancet. 1986;1 (8476):307-310.

20. de Vet HC, Terwee CB, Knol DL, Bouter LM. When to use agreement versus reliability measures. J Clin Epidemiol. 2006;59(10):1033-1039.

21. Spronk I, Polinder S, Haagsma JA, et al. Patient-reported scar quality of adults after burn injuries: a five-year multicenter follow-up study. Wound Repair Regen. 2019;27:406-414.

22. Kallidonis P, Kyriazis J, Kamal W, Porpiglia F, Liatsikos E. Hybrid laparoendoscopic single-site surgery of upper urinary tract with the use of mini-laparoscopic instruments: cosmetic outcome and midterm oncological outcome. World J Urol. 2016;34(9):1221-1228.

23. Gencdal S, Aydogmus H, Aydogmus S, Kolsuz Z, Kelekci S. Minilaparoscopic versus conventional laparoscopic surgery for benign adnexal masses. J Clin Med Res. 2017;9(7):613-617.

24. Pini G, Goezen AS, Schulze M, Hruza M, Klein J, Rassweiler JJ. Smallincision access retroperitoneoscopic technique (SMART) pyeloplasty in adult patients: comparison of cosmetic and post-operative pain outcomes in a matched-pair analysis with standard retroperitoneoscopy: preliminary report. World J Urol. 2012;30(5):605-611.

25. Rumsey N, Clarke A, White P. Exploring the psychosocial concerns of outpatients with disfiguring conditions. J Wound Care. 2003;12(7): 247-252.

26. Serebrakian AT, Pickrell BB, Varon DE, et al. Meta-analysis and systematic review of skin graft donor-site dressings with future guidelines. Plast Reconstr Surg Glob Open. 2018;6(9):e1928.

27. Radharaman PK, Ajai KS, Sharma RK. The role of recruited minced skin grafting in improving the quality of healing at the donor site of splitthickness skin graft-A comparative study. Burns. 2019;45(4):923-928.

28. Lindford AJ, Kaartinen IS, Virolainen S, Kuokkanen HO, Vuola J. The dermis graft: another autologous option for acute burn wound coverage. Burns. 2012;38(2):274-282. 
29. Legemate $\mathrm{CM}$, Lucas $\mathrm{Y}$, Oen I, van der Vlies $\mathrm{CH}$. Regrafting of the Split-thickness skin graft donor-site: is it beneficial? J Burn Care Res. 2020;41(1):211-214.

\section{SUPPORTING INFORMATION}

Additional supporting information may be found online in the Supporting Information section at the end of this article.
How to cite this article: Legemate CM, Ooms PJ, Trommel N, et al. Course of scar quality of donor sites following split skin graft harvesting: Comparison between patients and observers. Wound Rep Reg. 2020;1-8. https://doi.org/10.1111/wrr. $\underline{12840}$ 